This is the author's final, peer-reviewed manuscript as accepted for publication. The publisher-formatted version may be available through the publisher's web site or your institution's library.

\title{
Ethanol fermentation from food processing waste
}

Kara Walker, Praveen Vadlani, Ronald Madl, Philip Ugorowski, Keith L. Hohn

\section{How to cite this manuscript}

If you make reference to this version of the manuscript, use the following information:

Walker, K., Vadlani, P., Madl, R., Ugorowski, P., \& Hohn, K. L. (2013). Ethanol fermentation from food processing waste. Retrieved from http://krex.ksu.edu

\section{Published Version Information}

Citation: Walker, K., Vadlani, P., Madl, R., Ugorowski, P., \& Hohn, K. L. (2013). Ethanol fermentation from food processing waste. Environmental Progress \& Sustainable Energy, 32(4), 1280-1283.

Copyright: ( $) 2012$ American Institute of Chemical Engineers

Digital Object Identifier (DOI): doi:10.1002/ep.11700

Publisher's Link: http://onlinelibrary.wiley.com/enhanced/doi/10.1002/ep.11700/

This item was retrieved from the K-State Research Exchange (K-REx), the institutional repository of Kansas State University. K-REx is available at http://krex.ksu.edu 


\title{
Ethanol fermentation from food processing waste
}

Kara Walker ${ }^{1}$, Praveen Vadlani ${ }^{2}$, Ronald Madl ${ }^{2}$, Philip Ugorowski ${ }^{3}$, Keith L. Hohn ${ }^{4 *}$

${ }^{1}$ Kansas State University Research Experiences for Undergraduates (REU) Program, Manhattan, Kansas

${ }^{2}$ Department of Grain Science and Industry, Kansas State University, Manhattan, KS 66506

${ }^{3}$ Department of Mechanical and Nuclear Engineering, Kansas State University, Manhattan, KS 66506

${ }^{4}$ Department of Chemical Engineering, Kansas State University, Manhattan, KS 66506

E-mail: hohn@ksu.edu

* Correspondence: Keith L. Hohn, Department of Chemical Engineering, Kansas State University, Manhattan, KS 66506

Keywords: ethanol, fermentation, food waste, distillation, renewable energy

\begin{abstract}
This study focuses on the use of restaurant waste for production of ethanol. Food wastes (corn, potatoes, and pasta) were converted to ethanol in a two-step process: a two-part enzymatic digestion of starch using alpha-amylase and glucoamylase and then fermentation of the resulting sugars to ethanol using yeast. Because of the low initial composition of starch in the food waste, low ethanol concentrations were achieved: at best $8 \mathrm{mg} / \mathrm{ml}$ ethanol ( $0.8 \%$ by mass). Ethanol concentration increased with increasing enzyme dosage levels. Calculations were conducted to evaluate whether waste heat from restaurant waste could be used to drive flash vaporization to
\end{abstract}


purify ethanol. If the solution produced by fermenting food waste is flashed at a temperature of $99.7^{\circ} \mathrm{C}, 77 \%$ of the ethanol is recovered in a vapor stream with 1.14 mole $\%$ ethanol (2.87 mass $\%$ ). Waste heat could provide over a third of the energy for this vaporization process. If 4 mole $\%$ ethanol could be produced in the fermentation step by increasing the initial starch content in the waste solution and improving the fermentation process, then a single flash at $98.9^{\circ} \mathrm{C}$ will recover nearly $99 \%$ of the ethanol, giving a mass concentration of ethanol of $10.3 \%$, which is similar to that achieved in industrial grain fermentation.

\section{Introduction}

Ethanol has been found to provide significant environmental benefits when used in fuel blends to reduce smog emissions in vehicles [1]. For example, one study showed that the production and combustion of ethanol compared to gasoline reduces GHG emissions by $12 \%$ [2]. However, our ability to use ethanol as a replacement for gasoline is limited because the feedstock currently used to produce ethanol in the United States (corn) is also valuable as food and feed. Due to an increase in fuel ethanol production to meet the federal mandates for renewable fuel standards, the consumption of corn has accordingly increased, thereby impacting the corn supply to food and feed industries. Some claim that the price of corn has risen because of its use to produce ethanol, but this is controversial because petroleum prices have simultaneously increased as another driver for rising food prices.

One potential solution to this production limitation for ethanol is to identify sugar sources that do not have high-value food uses [1]. Though ethanol is primarily made from corn in the 
US and from sugarcane in Brazil [3], other crops such as grain sorghum [4], pearl millet [5], and rye and triticale [6] have been evaluated for ethanol production and promising yield and conversion efficiency have been attained. Researchers have also evaluated using wheat stillage [7] and crop wastes $[1,8,9]$ for ethanol production. A study from the Environmental and Energy Study Institute (EESI) explores the options for reusing food processing and crop waste [10]. This study reports that "in the potato industry, the rule of thumb is that $50 \%$ of the potato goes out as finished product, while the remainder (roughly 223,403 thousand-hundredweight in 2007) is wasted". EESI suggests new reuse processes that captures this waste and converts it to starch cakes that can be resold to food and animal feed producers. They estimate that "each 100 tons of processed potato yields 2-3 tons of starch, which has a resale value of about $\$ 180$ once recaptured." Additionally, the study suggests biofuel production from food processing wastewater.

Only a few studies have looked at fermentation of food wastes[11-14]. These studies have been conducted in Korea, where food wastes are particularly high in carbohydrates (as high as $65 \%$ of total solids)[11]. In these studies, food waste is mechanically crushed to produce a fermentable solution with high amounts of carbohydrates. Han and coworkers reported an ethanol product from food residues with a concentration of $60 \mathrm{~g} / \mathrm{ml}$ in $120 \mathrm{~h}$ of fed-batch fermentation using Saccharomyces italicus KJ[13]. Hong and coworkers converted food residues to ethanol by simultaneous saccharification with an amylolytic enzyme complex and fermentation with the yeast, Saccharomyces cerevisiae[12]. About $36 \mathrm{~g} / \mathrm{ml}$ ethanol was obtained from $100 \mathrm{~g} / \mathrm{ml}$ food residue in $48 \mathrm{~h}$ of fermentation. 
This study focuses on a different type of food waste for use in making ethanol: the cooking waste from boiling potatoes, pasta, and corn. The disadvantage of this type of waste is a low initial concentration of carbohydrates, but an advantage is that the solution is hot, so it may be possible to recover some of this heat to drive an ethanol purification step. Figure 1 shows a process envisioned for fermenting kitchen wastes to ethanol. The process consists of three main parts: a heat exchanger, a fermenter, and a flash vessel. The hot water (containing starches) used to prepare food (pasta as an example) transfers energy to a second fluid, lowering the temperature of the starch-containing water so that it can be fermented at $\sim 30^{\circ} \mathrm{C}$. Following fermentation, the product stream is heated in a one-stage flash vaporization process to concentrate the ethanol produced during fermentation. The fluid used to remove heat from the starch solution provides some of the heat for this process. Through this overall process, an ethanol solution is produced from cooking waste with use of little additional external energy.

The purpose of this work was to evaluate this concept through both experimentation and simulation. Fermentation of different kitchen wastes was conducted to determine the concentration of ethanol that could be produced. Calculations were then conducted to evaluate the flash vaporization process and whether this process could be sustained using only the energy derived from the original starch solution. The key novelty in this work is the use of waste material, in the form of carbohydrates in cooking wastes, and waste heat, in the form of high temperature water, to produce ethanol. In this way, ethanol can be produced inexpensively using a feedstock that is otherwise thrown away. 


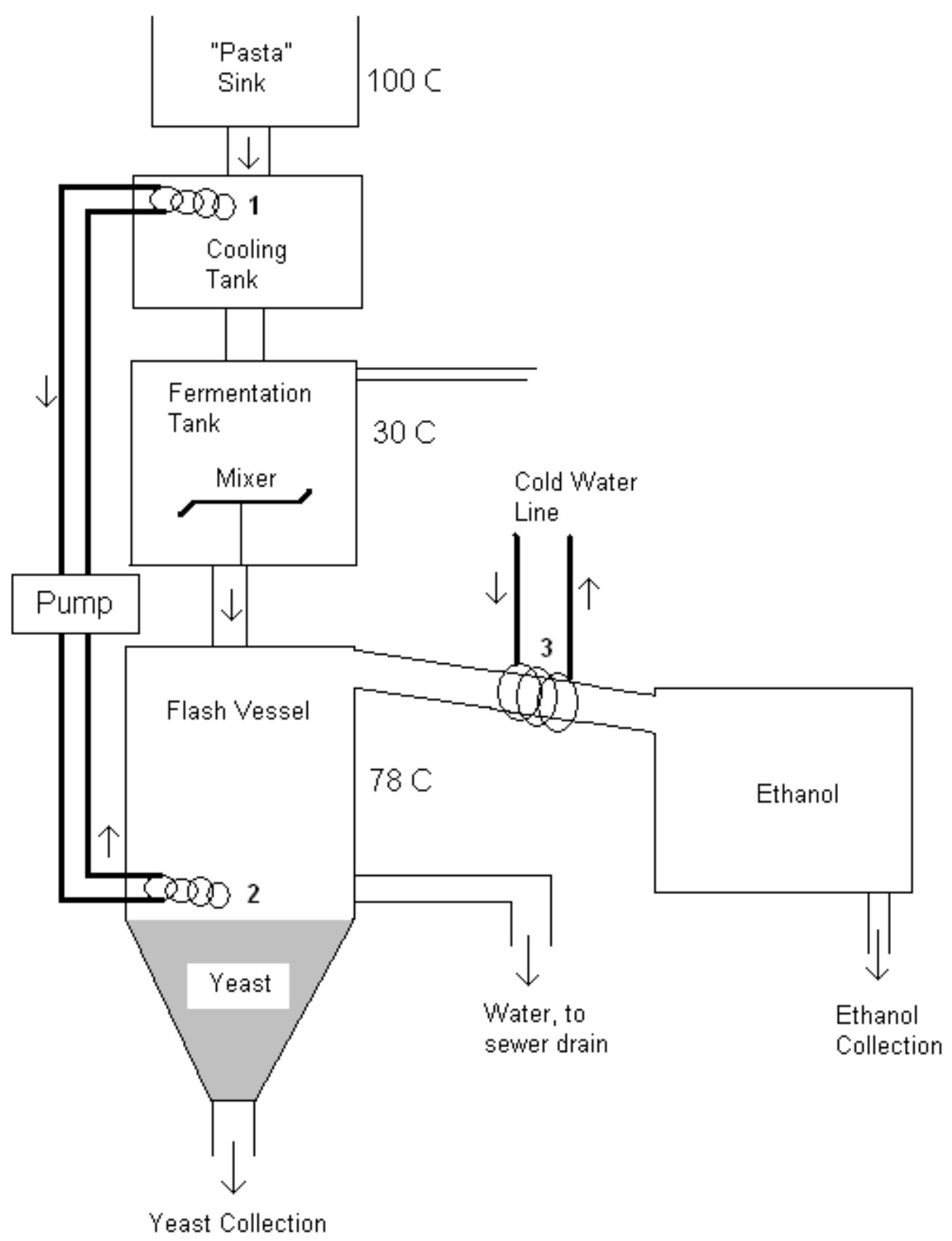

Figure 1: Diagram of proposed in-restaurant ethanol production 


\section{Materials and Methods}

\subsection{Sample Preparation}

Food waste samples: corn, pasta, and two sources of potatoes, were obtained from Derby Dining Center, Kansas State University. The samples were boiled for approximately 10-12 minutes (corn and pasta samples) and 45 minutes (without peels for the potato samples). Each sample was frozen after collection and then temperature-controlled throughout the course of experimentation. The $\mathrm{pH}$ of each sample was adjusted to about 6.0 using $0.1 \mathrm{M} \mathrm{HCl}$ or $\mathrm{NaOH}$ solutions before enzyme digestion experiments.

\subsection{Analysis}

\subsubsection{High Performance Liquid Chromatography (HPLC)}

Glucose and Ethanol quantification by HPLC:

About $5 \mathrm{ml}$ of sample from shake flasks and fermenters at different time intervals were centrifuged at 5,000 rpm for $10 \mathrm{~min}$ and the supernatant was collected in Eppendorff tubes. Analysis before any experimentation gave an initial glucose profile. Analysis after enzyme digestion showed starch conversion to two abundant sugars: glucose and maltose. Analysis after fermentation showed glucose conversion to ethanol. In each case, samples were prepared by taking $1 \mathrm{~mL}$ of the sample in an Eppendorf tube and centrifuging at $4{ }^{\circ} \mathrm{C}$ for $5-10$ minutes at 13,000 rpm. After centrifugation, the samples were diluted 10:1 with distilled water and filtered 
using $0.45 \mu \mathrm{m}$ syringe filters and filter attachment. The samples were then transferred to the appropriate HPLC vial and refrigerated until analysis.

A Shimadzu HPLC equipped with a refractory index detector (RID) and CTO-20A column oven at $80^{\circ} \mathrm{C}$ was used for analyses [3, 4]. HPLC-grade water was used as the mobile phase with a flow rate of $0.6 \mathrm{ml} / \mathrm{min}$. A Rezex-Organic acid column (Phenomenex) was used for separation and quantification of glucose and ethanol. HPLC data were acquired by using Lab Solutions software (Shimadzu).

\subsubsection{Iodine Test}

Three drops of iodine were added to $1 \mathrm{~mL}$ of each sample to test for starches. The presence of starches is denoted by a blue color due to the starch-iodine complex. Dextrins present produce a brown color. The samples were analyzed using a spectrophotometer with a known starch concentration as a standard.

\subsection{Enzyme Digestion}

\subsubsection{Alpha-Amylase}

A $125 \mathrm{~mL}$ Erlenmeyer flask was used with a stopper and aluminum foil for both digestions. Fifty $\mathrm{mL}$ of each sample was added to the flask followed by $50 \mu 1$ of $\alpha$-amylase (Liquozyme SC, $240 \mathrm{KNU} / \mathrm{g}$; Novozyme, Franklinton, NC, where $1 \mathrm{KNU}$ is the amount of enzyme which breaks down $5.26 \mathrm{~g}$ of starch per hour by Novozyme's standard method for determination of $\alpha$-amylase). The dosage quantity was increased to $2 X, 3 X$, and $4 X$ of initial 
value for subsequent experiments. The experiments were performed for two hours in a water bath maintained at $85^{\circ} \mathrm{C}$ for the first digestion $[3,4]$. The bath was covered with aluminum foil to keep the temperature constant. After two hours, the samples were removed and cooled with running water.

\subsubsection{Glucoamylase}

Once the samples were cooled to $40^{\circ} \mathrm{C}, 400 \mu 1$ of glucoamylase (Spirizyme, 750 Novo Glucoamylase Unit (AGU)/g; Novozymes, Franklinton, NC) was added and the flasks were incubated for an additional $2 \mathrm{~h}$ at $100 \mathrm{rpm}[3,4]$. Again, the bath was covered with aluminum foil to maintain constant temperature. After this step, the flasks were cooled and samples were collected for HPLC analyses

\subsection{Fermentation}

After the two-part enzyme digestion, the samples were inoculated with Saccharomyces cerevisiae (yeast) inoculum. The broth was prepared by adding about $0.5 \mathrm{~g}$ dry yeast to $10.48 \mathrm{~g}$ of YM Broth in $500 \mathrm{~mL}$ distilled $\mathrm{H}_{2} \mathrm{O}$ that had been sterilized for 15 minutes at $121^{\circ} \mathrm{C}$ in the autoclave. The yeast broth was incubated for 24 hours at $30^{\circ} \mathrm{C}$ and $200 \mathrm{rpm}[3,4]$.

Each sample was sterilized under UV light for 30-45 minutes before inoculation.

Simultaneously, Eppendorf tubes, distilled $\mathrm{H}_{2} \mathrm{O}$, and pipette tips were sterilized for 15 minutes at $121^{\circ} \mathrm{C}$ in the autoclave. The yeast broth was diluted to $10-100 \mathrm{X}$ concentration and $1 \mathrm{~mL}$ was 
added to each sample. The samples were placed in a shaker incubator at $30^{\circ} \mathrm{C}$ and $120-150 \mathrm{rpm}$ for 24 hours.

\subsection{Flash Vaporization}

Simulations were completed using the program Aspen Plus 7.2 to determine the vaporliquid compositions at different temperatures. An isothermal flash at atmospheric pressure was conducted assuming an aqueous solution containing $8 \mathrm{mg} / \mathrm{ml}$ ethanol. The other components in the fermentation broth were not considered in this calculation, but are not expected to change the vapor composition. The heat duty required at various temperatures was calculated to determine whether the energy produced by cooling the food waste stream to the fermentation temperature would be sufficient to drive flash vaporization.

\section{Results and Discussion}

After initial HPLC analysis, glucose levels were determined to be minimal (Figure 2). These results prompted a starch test where samples A, B, C, and D were found to contain approximately $0.267 \mathrm{mg} / \mathrm{mL}, 0.166 \mathrm{mg} / \mathrm{mL}, 0.0175 \mathrm{mg} / \mathrm{mL}$, and $0.058 \mathrm{mg} / \mathrm{mL}$ starch, respectively. With starches present, a two-part enzyme digestion was completed to try to increase the glucose yield of the samples, and the results are shown in Figure 3. 


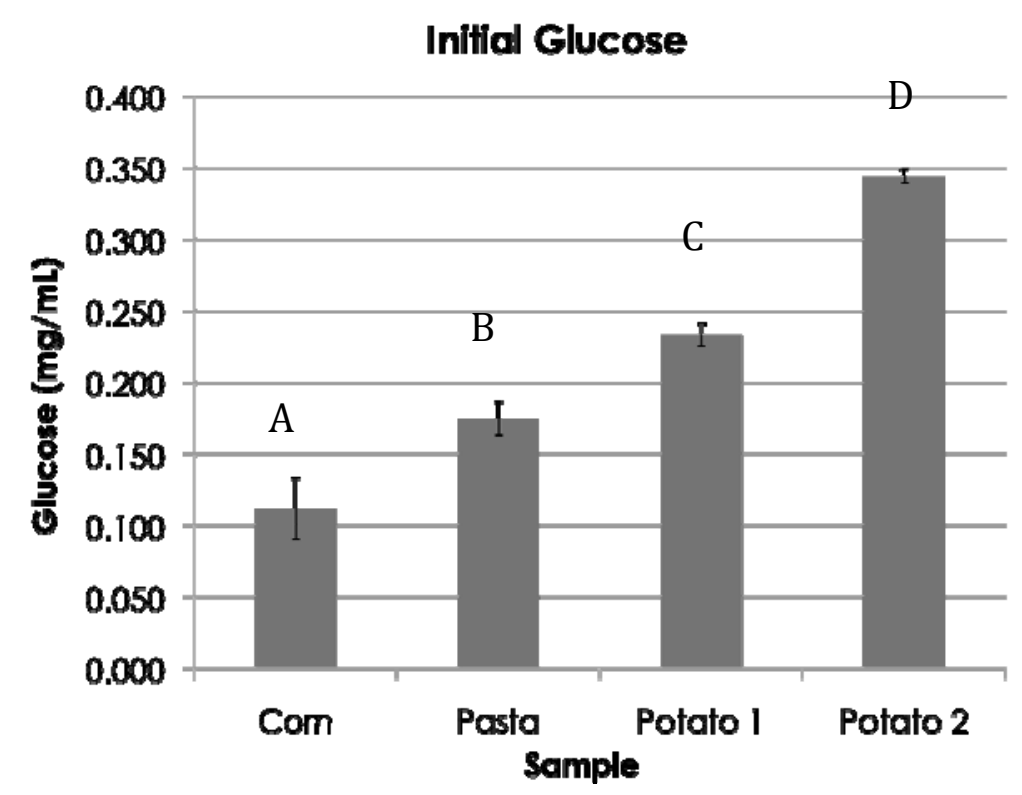

Figure 2: Initial glucose concentrations in each sample

\section{Glucose-Ethanol Conversion}

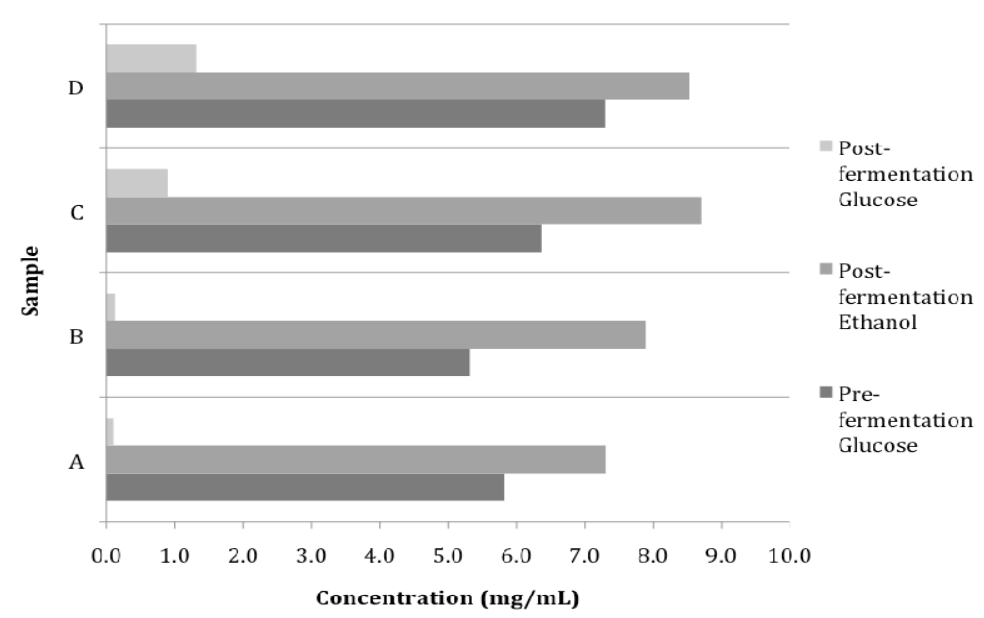

Figure 3: 1X Glucose-Ethanol Conversion. Sample A is for corn waste, sample $B$ is for pasta waste, and samples C and D are for potato waste.

On a mass basis, 1 gram of glucose can theoretically ferment to 0.511 grams of ethanol [15]. As seen in the Figure 3, based on the glucose consumed, the ethanol production appears to be higher than theoretical yield. These results lead to the conclusion that the enzyme digestion 
was not complete, but was accomplished by the yeast enzymes during fermentation. Incomplete digestion could be due to many factors including temperature and $\mathrm{pH}$. However, because the iodine test is a qualitative estimate of starches present, it is impossible to know exactly how much enzyme should be added. Therefore, the likely explanation of incomplete digestion is that there is not enough enzyme to completely break down the starch present in the samples. Using this hypothesis, several subsequent enzyme digestions were completed to optimize the glucose yield. The results are shown in Figure 4.

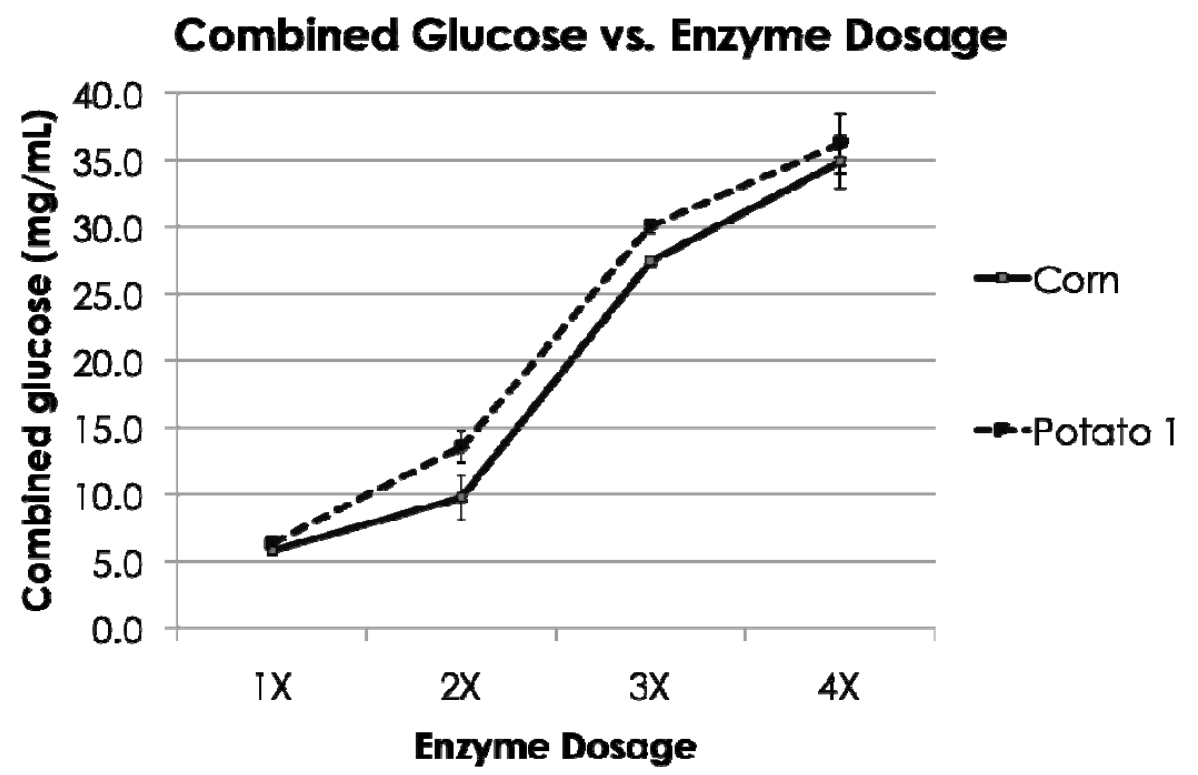

Figure 4: Enzyme optimization curve for high yield samples

As seen in Figure 4, increasing the enzyme dosage increases the glucose yield from both corn and potato feed stocks up to a $3 \mathrm{X}$ dosage. The $4 \mathrm{X}$ dosage did not show a significant increase in combined glucose from $3 \mathrm{X}$, so it can be concluded that the optimum dosage is 
between $3 \mathrm{X}$ and $4 \mathrm{X}$. The theoretical ethanol yield can be calculated by assuming the following reaction:

$$
1 \mathrm{C}_{6} \mathrm{H}_{12} \mathrm{O}_{6} \rightarrow 2 \mathrm{C}_{2} \mathrm{H}_{5} \mathrm{OH}+2 \mathrm{CO}_{2}+\text { energy (stored as ATP), }
$$

With a maximum of $30-35 \mathrm{mg} / \mathrm{mL}$ of combined glucose, the ethanol yield should be 15.3 $17.85 \mathrm{mg} / \mathrm{ml}$, which correlates to $1.53-1.79 \%$ by mass. This percentage is small when compared to the industry's 7-9\% ethanol before distillation. For this reason, a separation step is envisioned downstream of the fermentation, where the energy in the initial starch solution is used to vaporize the fermentation products and concentrate the ethanol.

To evaluate the potential of this step to concentrate the ethanol solution, flash calculations were made using Aspen Plus 7.2. An isothermal flash at atmospheric pressure was conducted on an aqueous solution containing $8 \mathrm{mg} / \mathrm{ml}$ ethanol. This concentration was chosen, even though it is very low, because it is the highest concentration we demonstrated experimentally (see Figure 3).

Figure 5 shows the results of the flash calculation. As expected, the amount of ethanol recovered increases with increasing temperature, while the mole percent of ethanol in the vapor decreases. The mole percent is very low at all temperatures ( $3 \mathrm{~mole} \%$ or less) because of the low initial concentration of ethanol in the solution. If we run the flash process at a temperature of $211.5^{\circ} \mathrm{F}$, we can recover $77 \%$ of the ethanol in a vapor stream with 1.14 mole $\%$ ethanol ( 2.87 mass \%).

The energy balance for the process shows that the waste heat can provide a significant fraction of the energy needed for flash vaporization, though additional energy will be needed. 
Assuming that the waste starch solution is a saturated liquid at its boiling point, it was found that for a total flow rate of $1 \mathrm{lb}-\mathrm{mol} / \mathrm{hr}$ the energy to cool the solution to an assumed fermentation temperature of $30^{\circ} \mathrm{C}$ was slightly more than a third of the energy needed to vaporize the fermentation products at $211.5^{\circ} \mathrm{F}$.

Clearly, a challenge for this process is the low ethanol concentration. If we could achieve 4 mole $\%$ ethanol from the fermentation by increasing the initial starch content and improving the fermentation process, then a single flash at $210^{\circ} \mathrm{F}$ will recover nearly $99 \%$ of the ethanol, giving a concentration of ethanol of $10.3 \%$, which is similar to that achieved in industrial grain fermentation. The energy requirements are much higher in this case (more ethanol is being evaporated), so the hot water provides a smaller percent of the total energy required (only 13\% given a total flow rate of $1 \mathrm{lb}-\mathrm{mol} / \mathrm{hr}$ ). 


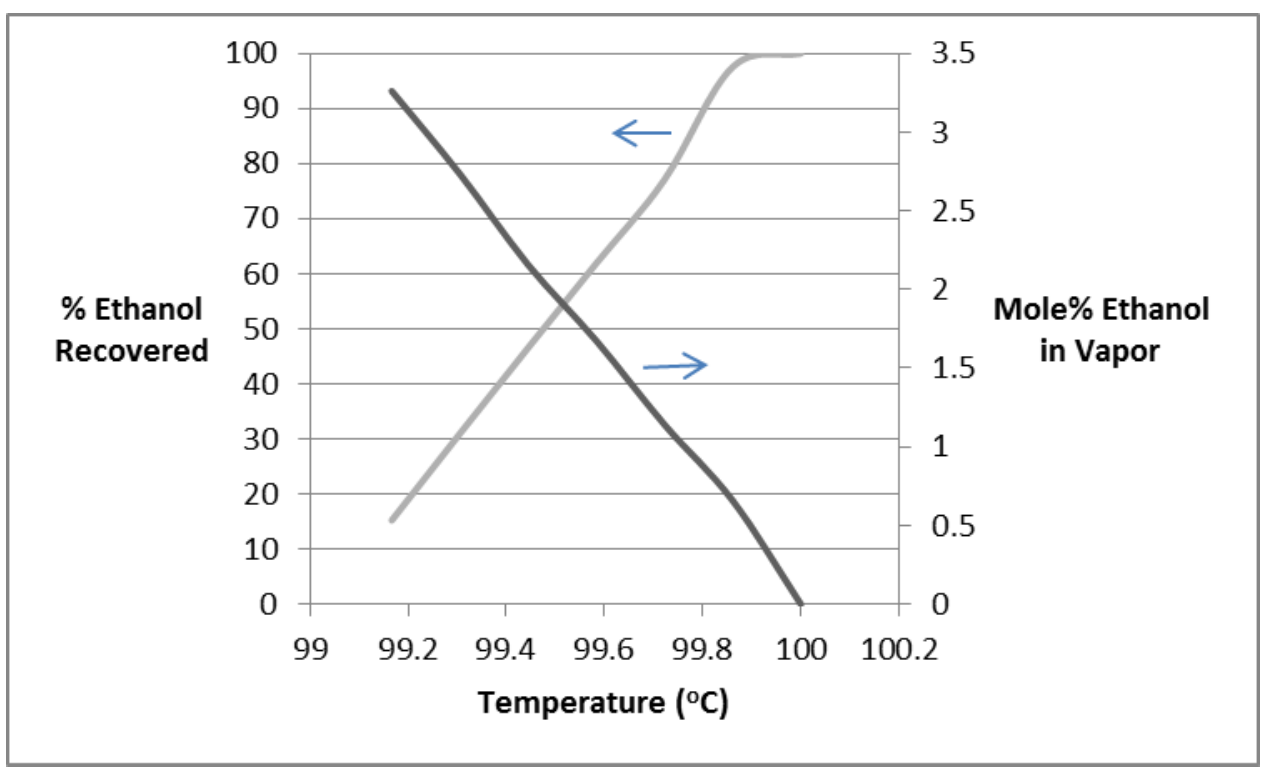

Figure 5: Percent recovery of ethanol in vapor phase and ethanol mole $\%$ in the vapor for a single-stage flash vaporization at different temperatures.

\section{Conclusion}

The feasibility of using waste starch from food preparation was evaluated. An integrated process was envisioned, where the starch solution was first digested using enzymes followed by fermentation to ethanol and flash vaporization of the ethanol solution using heat from the initial solution as a heat source. Experimental results showed that cooking waste could be converted to ethanol. Breaking down the starch to fermentable sugars was a critical step, and it was found that the optimum enzyme dosage was between 3 and 4 times the initial volumes $50 \mu \mathrm{l}$ and $400 \mu \mathrm{l}$ for alpha-amylase and glucoamylase, respectively (activity of the enzymes are shown in 
Materials section). Under these conditions, a final ethanol composition of $8 \mathrm{mg} / \mathrm{ml}$ was achieved. This is a low number because of the small initial concentration of starch. With this ethanol composition, a single flash at $99.7^{\circ} \mathrm{C}$ recovered $77 \%$ of the ethanol in the vapor, giving a final ethanol concentration of 2.87 mass $\%$. Thirty three $\%$ of the total energy needed for the flash vaporization could be provided by cooling the hot initial starch solution. The low concentration of starch limits the entire process. If this concentration can be increased so that digestion and fermentation yield a 4 mole $\%$ ethanol solution, the flash vaporization can produce a solution with greater than 10 mass $\%$ ethanol, similar to that achieved in industrial grain fermentation.

\section{Acknowledgements}

Financial support from the Earth, Wind, and Fire: Sustainable Energy in the $21^{\text {st }}$ Century REU program funded by the National Science Foundation Award \#0851799 is acknowledged and appreciated. The assistance by Professor Mary Molt with Kansas State University's Derby Dining Center is also acknowledged.

\section{References}

1. Kim S., Dale BE (2004) Global potential bioethanol production from wasted crops and crop residues. Biomass and Bioenergy, 26: 361-375

2. Hill, J, Nelson, E., Tilman, D., Polasky, S., Tiffany, D. (2006). Environmental, economic, and energetic costs and benefits of biodiesel and ethanol biofuels", PNAS, 103, 11206-11210.

3. Ananda N., Vadlani P.V., Madl R.L. (2010) Rice bran is an effective substitute for yeast extract in ethanol fermentation. Journal of Biobased Materials and Bioenergy, 5(1), 70-74. 
4. Ananda, N., Vadlani PV., Prasad PVV (2011) Evaluation of drought and heat stressed grain sorghum (Sorghum bicolor) for ethanol production. Industrial Crops and Products, 33 (3), 779-782.

5. Wu X., Wang D., Bean SR., Wilson JP (2006) Ethanol production from pearl millet using Saccharomyces cerevisiae. Cereal Chem., 83(2): 127-131

6. Wang S., Thomas KC., Ingledew WM., Sosulski K., Sosulski FW (1997) Rye and triticale as feedstock for fuel ethanol production. Cereal Chem., 74(5): 621-625

7. Davis L., Jeon Y-J., Svenson C., Rogers P., Pearce J., Peiris (2005) Evaluation of wheat stillage for ethanol production by recombinant Zymomonas mobilis. Biomass and Bioenergy, 29: 49-59

8. Vidmantiene D., Juodeikiene G., Basinskiene (2006) Technical ethanol production from waste of cereals and its products using a complex enzyme preparation. J Sci Food Agric., 86: 1732-1736

9. Champagne, P., Bioethanol from agricultural waste residues. Environmental Progress, 27: $51-57$

10. Hacker, J., Mattingly, J., Caputo, J. (2009) Food and Crop Waste: A Valuable Biomass Feedstock In Environmental and Energy Study Institute (EESI) brief, http://www.eesi.org/files/foodwaste_factsheet_finaldraft_040609_0.pdf.

11. Kim, J.H., Lee, J.C., Pak, D. (2011) Feasibility of producing ethanol from food waste. Waste Management, 31: 2121-2125.

12. Hong, Y.S., Yoon, H.H. (2011) Ethanol production from food residues. Boimass and Bioenergy, 35:3271-3275. 
13. Han, H.J., Li, H., Kim, S.J. (2006) Ethanol production by synchronous saccharification and fermentation using food wastes. Korean J. Biotechnol. Bioeng. 21: 474-478.

14. Kim, J.K, Oh, B.R., Shin, H.J., Eom, C.Y., Kim, S.W. (2008) Statistical optimization of enzymatic saccharification and ethanol fermentation using food waste. Process Biochem. 43: 1308-1312.

15. Moo-Young, Murray, (1985) Comprehensive Biotechnology The Principles, Applications, and Regulations of Biotechnology in Industry, Agriculture, and Medicine. Oxford, UK: Pergamon Press Ltd. 